03

\title{
Критерий подобия сверхзвукового обтекания цилиндра с передней высокопористой ячеистой вставкой
}

\author{
(C) С.Г. Миронов 1,2, Т.В. Поплавская ${ }^{1,2}$, С.В. Кириловский ${ }^{1,2}$, \\ A.A. Маслов ${ }^{1,2}$ \\ ${ }^{1}$ Институт теоретической и прикладной механики им. С.А. Христиановича \\ СО РАН, Новосибирск, Россия \\ ${ }^{2}$ Новосибирский национальный исследовательский государственный \\ университет, Новосибирск, Россия \\ E-mail: mironov@itam.nsc.ru
}

Поступило в Редакцию 18 октября 2017 г.

Приведены результаты экспериментального и численного исследования влияния отношения диаметра цилиндра с передней газопроницаемой пористой вставкой из вспененного никеля к диаметру пор вставки на аэродинамическое сопротивление модели в сверхзвуковом потоке $\left(M_{\infty}=4.85,7\right.$ и 21$)$. Получена аналитическая зависимость нормированного коэффициента аэродинамического сопротивления от параметра, в который входит отношение диаметра цилиндра к диаметру пор вставки и число Маха. Данный параметр предложен в качестве критерия подобия в задаче сверхзвукового обтекания цилиндра с передней высокопористой ячеистой вставкой.

DOI: 10.21883/PJTF.2018.06.45761.17087

Критерии аэродинамического подобия позволяют судить об аэродинамических характеристиках (например, сопротивлении) реального объекта по результатам исследований их небольших моделей. Известными критериями подобия в аэродинамике являются число Маха и 
число Рейнольдса. В число Рейнольдса входит один из характерных геометрических размеров обтекаемого тела. В случае обтекания тел с газопроницаемыми пористыми вставками в список характерных размеров добавляется еще и размер пор материала. При этом значения чисел Рейнольдса, вычисленные с использованием масштаба тела и масштаба пор, могут существенно различаться.

В настоящее время работы в области применения газопроницаемых пористых материалов в современной аэродинамике ведутся в двух основных направлениях: использование пористых материалов для подавления акустических возмущений в пограничном слое для продления ламинарного режима течения [1-3] и управление обтеканием тел с газопроницаемыми пористыми вставками с целью снижения аэродинамического сопротивления [4-6] и повышения маневренности летательных аппаратов $[7,8]$.

В работах $[4,9,10]$ экспериментально и с помощью численного моделирования были получены коэффициенты сопротивления цилиндра с передней газопроницаемой вставкой из ячеисто-пористого никеля (пористость 95\%) в сверхзвуковом потоке (число Маха $M_{\infty}=4.85$ ) в диапазоне чисел Рейнольдса $\operatorname{Re}_{D}=(0.1-2) \cdot 10^{5}$, вычисленных по скорости набегающего потока и диаметру цилиндра $D$. Эксперимент и расчет показали слабую зависимость коэффициента сопротивления модели от $\mathrm{Re}_{D}$. C другой стороны, коэффициент сопротивления оказался существенно зависящим от диаметра пор $d$ при постоянном диаметре цилиндра. Это инициировало экспериментальное и численное исследование влияния отношения диаметра цилиндра к диаметру пор передней высокопористой вставки на коэффициент аэродинамического сопротивления в сверхзвуковом потоке, результаты которого представлены в настоящей работе.

Эксперименты по измерению коэффициента аэродинамического сопротивления $C_{x}$ цилиндра с передней цилиндрической пористой вставкой из высокопористого ячеистого никеля при варьировании диаметра цилиндра $D=14.8,24$ и $34 \mathrm{~mm}$ и диаметра пор $d=1,2,3$ и $4 \mathrm{~mm}$ газопроницаемой передней вставки (рис. 1) проводились в сверхзвуковой аэродинамической трубе Т-327 ИТПМ СО РАН. Таким образом, были испытаны геометрически подобные модели с 12 значениями отношения $D / d$. Условия в потоке были следующими: числа Маха $M_{\infty}=4.85$, 7 и 21 , единичные числа Рейнольдса $\operatorname{Re}_{1 \infty}=2.7 \cdot 10^{6}, 1.5 \cdot 10^{6}$ и $0.6 \cdot 10^{6} \mathrm{~m}^{-1}$ соответственно. Во всех экспериментах отношение длины 


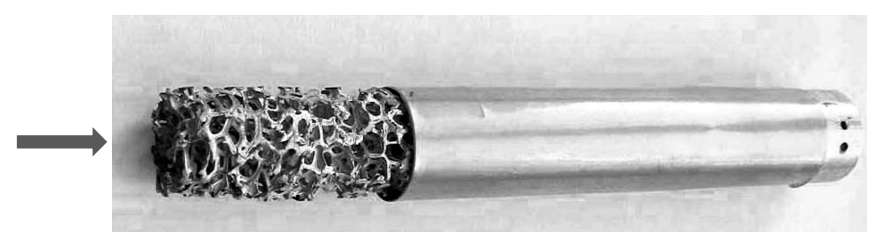

Рис. 1. Экспериментальная модель цилиндра с передней высокопористой вставкой из вспененного никеля.

пористой вставки к диаметру цилиндра было не менее 2, когда величина нормированного коэффициента аэродинамического сопротивления $C_{x} / C_{x 0}$ перестает изменяться [10]. Здесь $C_{x 0}-$ коэффициент аэродинамического сопротивления цилиндра без передней пористой вставки. В экспериментах величина $C_{x} / C_{x 0}$ определялась как отношение силы сопротивления цилиндра с передней пористой вставкой к силе сопротивления сплошного цилиндра. Сила сопротивления измерялась трехкомпонентными тензовесами.

С целью получения подробной картины течения было выполнено численное моделирование осесимметричного обтекания цилиндра с передними вставками из ячеисто-пористого материала при различных отношениях $D / d$. Решалась система двумерных уравнений Навье-Стокса, осредненных по Рейнольдсу, с использованием $k-\omega$-SST-модели турбулентности. К уравнениям, записанным в виде системы законов сохранения в цилиндрической системе координат $x r$ ( $x$ - осевая координата, $r$ - радиальная координата), добавляется уравнение состояния совершенного газа. Задача обтекания цилиндра решалась с использованием неявных схем второго порядка точности по пространству. Для аппроксимации конвективных потоков использовался Roe-FDS-метод расщепления c TVD-ограничителем для сохранения монотонности решения вблизи разрывов и локальных экстремумов течения. Рассматривалось обтекание полной модели, включающей скелет пористой вставки и сплошной цилиндр, общей длиной $100 \mathrm{~mm}$.

В расчетах использовалась скелетная модель пористой среды в виде системы соосных колец разного диаметра, расположенных в шахматном порядке [11]. В плоскости осевого сечения данная система колец (каркас пористого материала) представляет собой набор непроницаемых квадратных элементов, расположенных в шахматном

Письма в ЖТФ, 2018, том 44, вып. 6 

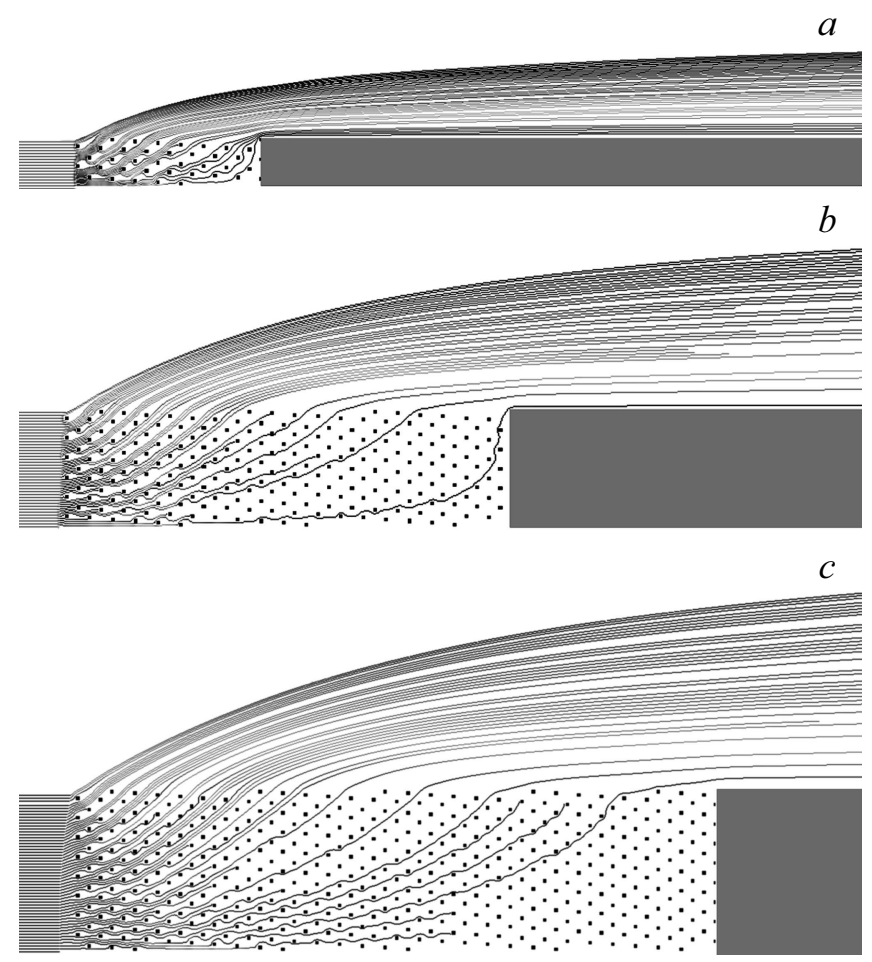

Рис. 2. Поля линий тока в нормальном направлении к оси $x$ при обтекании цилиндра с пористой вставкой, $d=1 \mathrm{~mm}, M_{\infty}=7, p_{\infty}=186 \mathrm{~Pa}, T_{\infty}=51 \mathrm{~K}$, $\operatorname{Re}_{1 \infty}=2.7 \cdot 10^{6} \mathrm{~m}^{-1} . D=6(a), 14.5(b), 20 \mathrm{~mm}(c)$.

порядке. Расстояние между элементами каркаса в радиальном и осевом направлениях равнялось диаметру пор, а объем, занимаемый каркасом, подбирался из расчета соответствия величины пористости реальному ячеисто-пористому материалу.

Проекция расчетной области на плоскость $x r$ представляет собой прямоугольник, нижняя сторона которого совпадает с осью симметрии цилиндра. Внутри пористой вставки расчетная область покрывалась равномерной прямоугольной расчетной сеткой, вне пористой зоны расчетная сетка имела сгущение вблизи переднего торца модели и

Письма в ЖТФ, 2018, том 44, вып. 6 
к поверхностям цилиндра и пористого участка. Общее число ячеек составляло не менее 800000 и зависело от длины пористой зоны. В результате решения задачи были получены все газодинамические величины потока как вне газопроницаемой вставки, так и внутри пористого материала, в том числе величины коэффициента аэродинамического сопротивления.

Коэффициент сопротивления модели рассчитывался по формуле

$$
C_{x}=\frac{F}{0.5 \rho_{\infty} u_{\infty}^{2} S_{m}},
$$

где $\rho_{\infty}, u_{\infty}-$ плотность и скорость набегающего потока, $S_{m}-$ площадь миделя модели, $F$ - аэродинамическая сила, включающая в себя силу давления, силу трения и силу волнового сопротивления. Сила $F$ вычислялась по разнице величин полного импульса потока перед головной ударной волной и в плоскости заднего торца цилиндра (интегральные величины по площади рассматриваемого сечения).

На рис. 2 приведены поля линий тока при обтекании цилиндров разного диаметра $D=6,14.5$ и $20 \mathrm{~mm}$ с пористой передней вставкой длиной в два диаметра цилиндра, диаметром ячеек пористого материала $d=1 \mathrm{~mm}$ при $M_{\infty}=7$. Видно, что с ростом диаметра модели увеличивается угол отклонения линий тока от поверхности модели, что связано с более интенсивным истечением газа из пористой зоны большего диаметра. Поэтому эффективность воздействия пористой вставки на поток падает с ростом диаметра модели, что должно приводить к увеличению аэродинамического сопротивления. Проведенные параметрические расчеты и экспериментальные измерения показали, что компенсировать снижение эффективности пористой вставки можно, увеличивая диаметр ячеек пористого материала, что в целом снижает аэродинамическое сопротивление. Отсюда следует существование критерия подобия вида отношения диаметра модели к диаметру пор материала.

На рис. 3, $а$ приведены экспериментальные и расчетные зависимости нормированного коэффициента аэродинамического сопротивления $C_{x} / C_{x 0}$ от отношения $D / d$ для относительной длины пористой вставки не менее 2. Видно увеличение коэффициента аэродинамического сопротивления с ростом величины $D / d$. Совпадение расчетных и экспериментальных данных находится в пределах точности измерений. Наблюдаемый разброс расчетных данных связан с дискретной природой

Письма в ЖТФ, 2018, том 44, вып. 6 

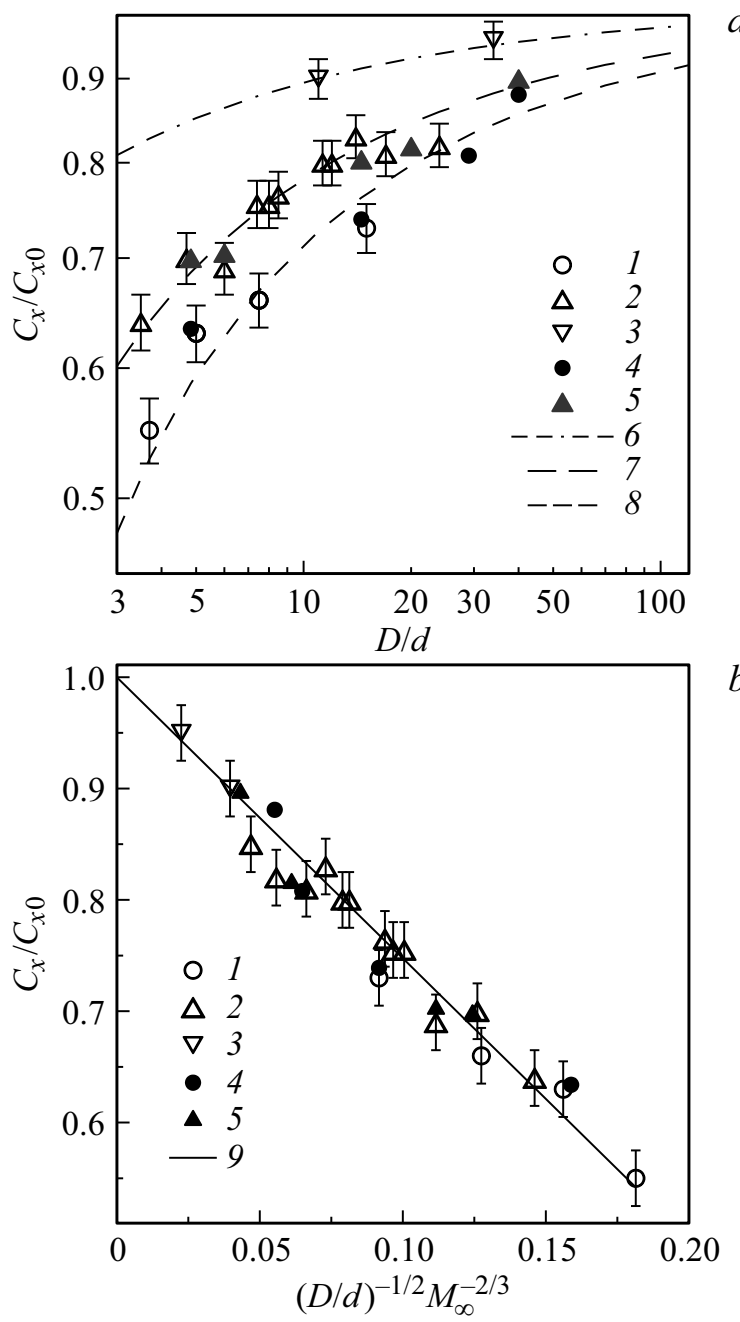

Рис. 3. Расчетные и экспериментальные данные для нормированного коэффициента сопротивления цилиндра с пористой вставкой в зависимости от величины отношения диаметра модели к диаметру пор $(a)$ и в зависимости от параметра подобия (2) $(b) .1-3$ - эксперимент при $M_{\infty}=4.85,7$ и $21 ; 4,5$ - расчетные данные при $M_{\infty}=4.85$ и 7; 6-9- обобщающая зависимость (1).

Письма в ЖТФ, 2018, том 44, вып. 6 
скелетной модели, которая диктует необходимость построения структуры пористого материала из конечного и целого числа элементов. Это порождает незначительные (менее $0.5 \%$ ) вариации коэффициента пористости при изменении диаметра модели $D$ и, как следствие, вариации сопротивления.

Экспериментальные и расчетные данные аппроксимируются единой зависимостью

$$
\frac{C_{x}}{C_{x 0}}=1-\frac{2.525}{\sqrt{D / d}} M_{\infty}^{-2 / 3} .
$$

Рис. $3, b$ показывает линейную зависимость нормированного коэффициента аэродинамического сопротивления от параметра

$$
(D / d)^{-1 / 2} M_{\infty}^{-2 / 3}
$$

и все экспериментальные и расчетные данные лежат на этой прямой. Это дает основание считать параметр $(D / d)^{-1 / 2} M_{\infty}^{-2 / 3}$ критерием подобия для коэффициента аэродинамического сопротивления тел с передними пористыми вставками.

Отношение $D / d$ можно рассматривать как отношение чисел Рейнольдса, вычисленных по диаметру цилиндра и по диаметру пор. Тогда, вероятно, физическим объяснением влияния найденного параметра подобия $(D / d)^{-1 / 2} M_{\infty}^{-2 / 3}$ на нормированный коэффициент сопротивления является отношение сил трения на всем цилиндре к силам трения в порах передней вставки цилиндра, а зависимость от числа Маха учитывает волновое сопротивление модели.

Таким образом, показано, что важным параметром моделирования обтекания цилиндра с передней пористой вставкой в сверхзвуковом потоке при $M_{\infty} \geqslant 5$ является отношение диаметра цилиндра к диаметру пор вставки. Получена аналитическая зависимость нормированного коэффициента аэродинамического сопротивления от параметра $(D / d)^{-1 / 2} M_{\infty}^{-2 / 3}$, в который входит отношение диаметра цилиндра к диаметру пор вставки и число Маха. Данный параметр можно считать критерием подобия в задаче сверхзвукового обтекания цилиндра с передней высокопористой ячеистой вставкой.

Работа выполнена при финансовой поддержке РФФИ (проект № 015-08-03867).

Письма в ЖТФ, 2018, том 44, вып. 6 


\section{Список литературы}

[1] Wartemann V., Lüdeke H., Sandham N.D. // AIAA J. 2012. V. 50. N 6. P. 12811290.

[2] Цырюльников И.С., Маслов А.А., Миронов С.Г., Поплавская Т.В., Кириловский С.А. // Письма в ЖТФ. 2015. Т. 41. В. 4. С. 61-67.

[3] Лукашевич С.В., Морозов С.О., Шиплюк А.Н. // ПМТФ. 2016. Т. 57. № 5. C. $127-133$.

[4] Фомин В.М., Миронов С.Г., Сердюк К.М. // Письма в ЖТФ. 2009. Т. 35. B. 3. C. $39-45$.

[5] Фомин В.М., Запрягаев В.И., Локотко А.В., Волков В.Ф., Луцикий А.Е., Меньшов И.С., Максимов Ю.М., Кирдяшкин А.И. // ПМТФ. 2010. Т. 51. № 1. C. 79-88.

[6] Фомин В.М., Постников Б.В., Ломанович К.А. // Письма в ЖТФ. 2015. T. 41. Вып. 18. С. 68-73.

[7] Hunter C.A., Viken S.A., Wood R.M., Bauer S.X.S. // AIAA Paper. 2001. N 2001-0249.

[8] Миронов С.Г., Маслов А.А., Цырюльников И.С. // Письма в ЖТФ. 2014. T. 40. B. 19. C. $83-88$.

[9] Бедарев И.А., Миронов С.Г., Сердюк К.М., Федоров А.В., Фомин В.М. // ПМТФ. 2011. Т. 52. № 1. С. 13-23.

[10] Миронов С.Г., Маслов А.А., Поплавская Т.В., Кириловский С.В. // ПМТФ. 2015. T. 56. № 4. C. 12-22.

[11] Миронов С.Г., Поплавская Т.В., Кирилловский С.В. // Теплофизика и аэромеханика. 2017. Т. 24. № 4. С. 647-650. 